\title{
Procedures Performed by the Hospitalist and Non-hospitalist
}

\author{
Romsai T. Boonyasai, MD, $M P H^{7}$, Rajiv Thakkar, $M D, M B A^{7}$, Patrick Alguire, $M D^{2}$, \\ and Robert S. Wigton, $M D^{3}$ \\ 'Johns Hopkins University School of Medicine, Baltimore, MD, USA; ${ }^{2}$ American College of Physicians, Philadelphia, PA, USA; ${ }^{3}$ University \\ of Nebraska Medical Center College of Medicine, Omaha, NE, USA.
}

The Authors' Reply. We thank Dr. Barsuk and colleagues their thoughtful analysis of our article. They raise important concerns about the generalizability of our findings. The SHM data is based on surveys of hospitalist groups, not individuals. Our study examined procedure rates of individual hospitalists. Although the absolute number of respondents in our dataset was small, it was obtained through a probability sample. The sampling frame was representative of the American College of Physicians (ACP) membership, stratified by geographic region of the US and year of graduation from medical school. ${ }^{1}$ We believe our findings are credible enough to warrant further examination of hospitalists' procedural practices.

Dr. Barsuk also noted that prior year performance rates for four of the nine core procedures were 50\% (lumbar puncture), 49\% (abdominal paracentesis), 44\% (thoracentesis), and 39\% (central line placement). However, we also found that hospitalists who reported doing a procedure performed a median of 5 lumbar punctures, 5 abdominal paracentesis, 5 thoracentesis, and 5.5 central line placements in the prior year, with interquartile ranges that varied between $2-30$ procedures. These procedure volumes suggest that while some hospitalists may perform bedside procedures regularly, the majority do not.

If further studies confirm these findings, hospitals, policy makers, residency accreditation committees, and professional societies should re-consider long-held assumptions about hospitalists' procedural practice patterns and how they might affect our patients. A growing literature shows that regular performance of procedures is associated with lower complication rates. ${ }^{2}$ If most hospitalists truly do perform only a handful of bedside procedures a year, it is debatable whether they are performing a sufficient number to remain comfortable, much less proficient with them. ${ }^{3}$ Further research into how hospitalists acquire and maintain procedural competence is neces-

Published online May 6, 2010 sary. Simulation-based competency training is one avenue for addressing this concern. ${ }^{4}$ Other potential solutions include referring patients to sub-specialty proceduralists and developing dedicated proceduralist services within hospitalist groups ${ }^{5}$. We believe that specific interventions should be tailored to local needs and resources, so as to ensure that our patients always receive high-quality inpatient care.

Romsai T. Boonyasai, MD, MPH; Johns Hopkins University School of Medicine, 4940 Eastern Avenue, Baltimore, MD 21224, USA (e-mail: romsai@jhmi.edu).

\section{REFERENCES}

1. Wigton RS, Alguire P. The declining number and variety of procedures done by general internists: a resurvey of members of the American College of Physicians. Ann Intern Med. 2007; 146:355-60.

2. Halm EA, Lee C, Chassin MR. Is volume related to outcome in health care? A systematic review and methodologic critique of the literature. Ann Intern Med. 2002;137(6):511-20.

3. Hicks CM, Gonzalez R, Morton MT, Gibbons RV, Wigton RS, Anderson RJ. Procedural experience and comfort level in internal medicine trainees. J Gen Intern Med. 2000;15(10):716-22.

4. Barsuk JH, Cohen ER, Feinglass J, McGaghie WC, Wayne DB. Use of simulation-based education to reduce catheter-related bloodstream infections. Arch Intern Med. 2009;169(15):1420-3.

5. Smith CC, Gordon CE, Feller-Kopman D, Huang GC, Weingart SN, Davis RB, Ernst A, Aronson MD. Creation of an innovative inpatient medical procedure service and a method to evaluate house staff competency. J Gen Intern Med. 2004;19:510-3.

J Gen Intern Med 25(9):897

DOI: $10.1007 /$ s11606-010-1374-1

(C) Society of General Internal Medicine 2010 